\title{
LA METÁFORA COMO TRASLATIO: DEL CÓDIGO VERBAL AL VISUAL EN LA CRÓNICA ILUSTRADA DE GUAMAN POMA*
}

La semiótica de la imagen se ha prestigiado como disciplina en las últimas tres décadas, a medida que ha ido independizándose de la iconografía tradicional, cuyos aportes empíricos aprovecha. $\mathrm{El}$ antecedente legítimo de esta nueva ciencia es, sin embargo, relativamente remoto: la Iconología de Cesare Ripa, cuya primera edición data de 1593. Mientras la iconografía intenta explicar lo que las imágenes representan ("declararlas"), la semiótica busca desmontar el mecanismo de la significación. La iconografía se ocupa del significante de la imagen, y la semiótica de la vida de los signos. En este sentido la contribución de Ripa es revolucionaria: su diccionario de imágenes simbólicas para artistas y emblematistas de la época constituye el primer intento de trabajar exclusivamente con aquellas imágenes cuyo significado es diferente de lo que literalmente ofrecen a la vista. Como tal, elaboró los conatos de una lógica de la imagen - ragionamiento d'imagini- que estableció de manera clara la diferencia entre formare (la constitución de la imagen) y dichiarare (su mera descripción, ligada logocéntricamente en la iconografía tradicional a las referencias textuales) ${ }^{1}$. Ya en el siglo $\mathrm{xx}$, los trabajos de Panofsky fundan la dimensión cultural de la iconografía moderna, al proponer tres etapas en el análisis de la imagen: el nivel primario, que revela los tópicos naturales (representación de entidades y eventos reconocidos por todos); el secundario, que examina los tópicos convencionales (motivos o imágenes determinados culturalmente); y el intrínseco, que atiende al contenido histórico y cultural de los dos primeros ni-

* La versión inglesa de este trabajo aparecerá en American Indian myths: Perspectives from inside out, en prensa en la Universidad de Indiana-Bloomington.

${ }^{1}$ Hubert Damisch, "Semiotics and iconography", en ThOMas A. SEbEOK (ed.), The tell-tale sign: A survey of semiotics, P. de Ridder, Lisse-Netherlands, 1975, pp. 28-33. 
veles$^{2}$. Y más recientemente, la semiótica de la imagen emerge en los notables esfuerzos de Umberto Eco y Roland Barthes por precisar la posibilidad de la codificación de los mensajes visuales, ante lo que Metz llamó el “impasse de la analogía": la etapa en que la noción de iconicidad del signo propuesta por Peirce detiene momentáneamente el progreso de la nueva disciplina ${ }^{3}$. Barthes plantea el problema en términos contundentes: ¿puede la representación analógica producir verdaderos sistemas de signos, o sólo colecciones de símbolos? ¿Hasta qué punto es compatible la analogía con la discontinuidad que parece necesaria para el proceso de la significación? Tanto Barthes como Eco aceptan la existencia de códigos icónicos, pero advierten contra su debilidad en tanto sistemas para comunicar significado, ya que ni son universales ni pueden existir fuera del texto. Barthes va más lejos cuando afirma que el código visual depende en última instancia de la escritura, ya que el sentido "sólo puede ser nombrado":

¿Es constante el mensaje lingüístico? ¿Hay un texto en una imagen o debajo o alrededor de ella? Para encontrar imágenes sin palabras, es necesario, sin duda, remontarse a sociedades parcialmente analfabetas, es decir, a una suerte de estado pictográfico de la imagen. De hecho, a partir de la aparición del libro, la relación entre el texto y la imagen es frecuente; esta relación parece haber sido poco estudiada desde el punto de vista estructural. ¿Cuál es la estructura significativa de la ilustración? ¿Duplica la imagen ciertas informaciones del texto, por un fenómeno de redundancia, o bien es el texto el que agrega una información inédita? El problema podría plantearse históricamente con relación a la época clásica, que tuvo una verdadera pasión por los libros ilustrados [...]. Actualmente, a nivel de las comunicaciones de masas, parece evidente que el mensaje lingüístico está presente en todas las imágenes: como título, como leyenda, como artículo de prensa, como diálogo de película, como fumetto. Vemos entonces que no es muy apropiado hablar de una civilización de la imagen: somos todavía, y más que nunca, una civilización de la escritura... ${ }^{4}$

${ }^{2}$ ERwin PANofsky, Studies in iconology: Humanistic theory in the art of Renaissance, Oxford University Press, New York, 1939.

${ }^{3}$ La revista parisina Communications ha publicado buena parte de este debate. Véanse, entre otros, los estudios de Christian MEtz, "Au-delà de l'analogie, l'image" (1970); Umberto Eco, "Sémiologie des messages visuels" (1970) y Roland Barthes, "Rhétorique de l'image" (1964).

4 Barthes, "Retórica de la imagen", en Comunicaciones. La semiología, Tiempo Contemporáneo, Buenos Aires, 1970, pp. 127-140 (trad. española del núm. de Communications de 1964). 
Para dar un ejemplo típico, Barthes examina la articulación de los códigos en el anuncio publicitario actual, apuntando hacia las dos funciones de la palabra escrita dentro de (o contigua a) la imagen: el anclaje (que pretende fijar el sentido, obligando al espectador a leer un mensaje previamente elegido por el autor del anuncio, entre otros posibles) y el relevo (que completa el mensaje visual al proveer un sentido que no está contenido en la imagen). El anclaje es la función usual del texto verbal que complementa la fotografía comercial o periodística; el relevo es la función del texto verbal en películas y caricaturas. Mientras que el anclaje vincula los códigos verbal y visual por analogía o equivalencia, el relevo los vincula por contigüidad: en otras palabras, el primero puede sustituir al signo icónico, y el segundo le añade información.

En este contexto teórico, el libro de Bernadette Bucher, La sauvage aux seins pendants ${ }^{5}$, constituye una aportación seminal a la naciente disciplina de la semiótica de la imagen. Describe cuidadosamente el proceso de la codificación visual, pese a las advertencias de Barthes y Eco en cuanto a su dificultad. Para ello traza las aventuras del signo icónico / motivo de referencia del título - la salvaje de senos caídos- en su doble juego de oposiciones paradigmáticas y sintagmáticas a través de los 400 grabados de los trece volúmenes de la colección de los Grandes viajes (1590-1634) del editor belga Theodore de Bry, corpus lo suficientemente amplio como para revelar, detrás de múltiples transformaciones, la recurrencia de elementos que constituyen estructuras significativas con mensajes cifrados. El modelo lingüístico, operante en esta incursión de Bucher en la semiótica de la imagen, no le impide percibir la especificidad de los mensajes visuales. Porque los textos verbales y los textos pictóricos se leen de manera diferente. Las distintas implicaciones de cada sistema de signos se perciben mejor cuando consideramos la traslación de códigos que caracteriza a la literatura ilustrada. Y no hay que perder de vista un hecho singular: los que estuvieron a cargo de la representación visual de algunas de las escenas descritas por el texto verbal de crónicas y libros de viaje sobre el Nuevo Mundo fueron artesanos europeos que nunca pusieron pie en América. De ahí que el re-

${ }^{5}$ Hermann, Paris, 1977. La University of Chicago Press ha publicado recientemente la traducción de este libro bajo el título Icon and conquest: A structural analysis of the illustration of de Bry's Great Voyages (1981). Recojo algunas de sus ideas en mi ensayo "La iconografía política de América: el mito fundacional en las imágenes católica, protestante y nativa', $N R F H, 32$ (1983), 448-461. 
sultado de semejante empresa fuera, más que una etnografía del aborigen, una etnografía de la mentalidad occidental en el momento del surgimiento de un etnocentrismo imperialista.

El estudio del material gráfico de De Bry lleva a Bucher a importantes conclusiones sobre los efectos de la traslación del código verbal al visual. El primero que pudo observar fue el de la reducción de atributos sensoriales en el léxico de las ilustraciones. La técnica del grabado - limitada al blanco y el negro- elimina el elemento del color, que con relación a las gentes del Nuevo Mundo tiene dos dimensiones esenciales: una natural (el color de la piel) y la otra cultural (la pintura cutánea y el color de los ornamentos). El resultado de la supresión del color es doble: por un lado empobrece la descripción etnográfica, pero por el otro - al eliminar el criterio físico más importante para la diferenciación racial - hace del indio desnudo un hombre igual, y relega la discriminación al ámbito de la cultura. Si bien este efecto es intrínseco sólo al medio del grabado en blanco y negro, los otros efectos que señala Bucher son el resultado obligado de la traslación del código verbal al visual. Un segundo efecto está en la pérdida de la negación como recurso retórico. La manera más fácil de describir una entidad desconocida es señalar aquello que no es (los indios carecen de casi todo lo que tienen los españoles); pero el dibujo figurativo no puede expresar la negación. Por ejemplo, la carencia de ropa occidental sólo se puede mostrar en un dibujo por medio de un cuerpo desnudo o semi-desnudo. Pero este cuerpo - la afirmación de otro tipo de realidad en sí mismo- necesita manifestarse según las convenciones gráficas de la época. En los siglos XVI y XVII no existía en Europa otra manera de representar la anatomía que la de reprodueir, o bien formas desnudas de proporciones clásicas, o monstruos medievales. En ambos casos, el mensaje resultante no es precisamente el de la falta de vestimenta, sino la afirmación de un tipo de humanidad ${ }^{6}$. El tercer efecto producido por la traslación de los códigos es la transformación de la comparación en metáfora. La imagen gráfica no posee el equivalente del medio sintáctico para conectar los dos términos de una comparación verbal; no le queda otro remedio que reducir la comparación a la sustitución o metáfora (la asimilación com-

${ }^{6}$ Para más sobre la propuesta de que la imagen no sabe sino afirmar, véase R. Mayenowa, "An analysis of some visual signs: Suggestions for discussion', JAN VAN DER ENG AND MoJMIR GRYGar (eds.), Structure of texts and semiotics of culture, Mouton, The Hague-Paris, 1973, p. 208. 
pleta del término comparado al comparable: en consecuencia, sólo éste es visible). La traslación de las negaciones y las comparaciones verbales a imágenes resulta - como señala Bucher- en una transformación tan radical del sentido que se aproxima a las metáforas de la poesía surrealista.

Siguiendo a Bucher, y ya que ella no provee un ejemplo de este tercer efecto, quisiera examinar una instancia de la metáfora como traslatio $^{7}$ del código verbal al visual en la crónica ilustrada del indio peruano Guaman Poma de Ayala (1615). De la traslatio resulta en este caso nada menos que la retórica de la denuncia del régimen colonial.

El texto del autor andino es comparable a los Grandes viajes de De Bry en tanto que incluye 398 dibujos y propone una tipología cultural del Nuevo Mundo, aunque aquí la perspectiva es nativista. Trasciende, y con mucho, a la mera literatura ilustrada: todos los dibujos a tinta son del mismo Guaman Poma, y no sólo complementan, sino que guían y preceden al texto escrito. Más aún: constituyen casi la mitad de la obra, y cada uno es contiguo a su contexto verbal inmediato.

Para mi análisis he seleccionado dos ilustraciones de la Nueva corónica y buen gobierno con sus respectivos textos verbales, que reproduzco de la edición crítica a cargo de Murra y Adorno (1980) ${ }^{8}$. La comparación de ambos -estructuralmente simétricos- revelará la emergencia de la metáfora como traslatio en el segundo.

La primera ilustración (de la primera parte del manuscrito, la Nueva corónica, una etnografía de la prehistoria andina) pertenece a la sección que versa sobre las instituciones incaicas. Muestra a un prisionero rodeado de animales salvajes en la cárcel destinada a los traidores.

La identidad de Guaman Poma es problemática. No es un mestizo, como Garcilaso Inca, sino que proclama descender de las dos dinastías reales del Perú prehispánico: los incas y los yarovilcas. A la vez que recomienda la justicia incaica de cara al régimen español, como yarovilca - descendiente de uno de los principales grupos étnicos sojuzgados por los incas - también la denuncia cuando habla de la "inquisición" o zancay: "con este miedo no se alsaua la tierra, pues que abía señores desendientes de los

${ }^{7}$ La traducción latina del término metáfora, de origen griego.

${ }^{8}$ Felipe Guaman Poma de Ayala, El primer nueva corónica y buen gobierno, eds. John V. Murra y Rolena Adorno, trad. y comentario de los textos quechuas por Jorge L. Urioste, Siglo XXI, México, 1980, 3 ts. 
rreys antigos que eran más que el inga'. El texto visual es ambiguo en tanto permite la lectura de dos mensajes contradictorios: la severidad de la justicia incaica 1) se presenta como ejemplar, 2) se denuncia por inhumana. Es interesante el hecho de que Guaman Poma no usa aquí un anclaje que pueda aclarar el mensaje visual (aquí el anclaje es pura nominación: un título bilingüe, y un subtítulo que repite la misma información), sino un relevo que reitera la ambigüedad de la imagen ${ }^{9}$.

Notamos que, por una parte, el prisionero, hablando en quechua, reconoce su culpa y la justicia de un castigo merecido: "zancay suclla micuuay huchazapa soncayta" (Cárcel, devora de una vez éste mi corazón pecador); por la otra, el patetismo de la queja deja al lector con la sospecha de que el castigo ha sido excesivo: "caypaccho yaya yumauarcanqui, mama uachauarcanqui"' (¿Y para esto, padre, me engendraste, madre, me pariste?). Aun cuando a los ojos de los incas el prisionero resulta un traidor, la ilustración lo presenta como un creyente pre-cristiano: "yaya pachacamac uanazac yaya" (Padre Creador del mundo, me enmendaré), " maypim canqui huchazapac camachic quispichihuay runacamac dios" (¿Dónde estás, Creador del pecador? Creador del hombre, Dios, líbrame). $\mathrm{Y}$ éste es precisamente el argumento subyacente en la justificación teleológica que hace Guaman Poma de la conquista: el indio andino prehispánico era cristiano:

... porque los rreys daquel tienpo fueron cri[s]tianos, temieron a Dios y a su justicia $[\ldots]$.

De cómo en aquel tienpo no se matauan ni se rrobauan ni se echaban maldiciones ni auía adúlteras ni ofensa en seruicio de Dios ni auía luxuria, enbidia, auaricia, gula, soberbia, yra, acidia, pereza. Y no auía deudas ni mentiras, cino todo uerdad, y con ello una sombrilla del conocimiento de Dios. Y abía mandamiento de Dios y la buena obra de Dios y caridad y temor de Dios y limosna se hazían entre ellos. Y tenían buena justicia y graue, temeroso de Dios...

Al andino prehispánico, naturalmente monoteísta, lo guiaba, según Guaman Poma, "una sombrilla del conocimiento de Dios", por el camino de las siete virtudes, lejos de los siete vicios. La vi-

${ }^{9}$ Para más sobre el empleo del anclaje y el relevo en los dibujos del autor andino, véase mi trabajo sobre "La crónica de Indias como texto cultural: articulación de los códigos icónico y lingüístico en los dibujos de la Nueva corónica de Guaman Poma", RevIb, 48 (1982), 461-531. 
sita temprana del apóstol San Bartolomé confirmó su fe intuitiva. Para ennoblecer sus credenciales ante el destinatario de su cartacrónica, Felipe III, Guaman Poma asegura descender directamente de esta edad de oro de la virtud, la cuarta era de indios, aucaruna, de la que provienen los yarovilcas.

Pero la idolatría incaica - continúa el cronista - hizo que los primeros andinos abandonaran el monoteísmo por el culto de las huacas (deidades telúricas). La versión de Guaman Poma del mito de origen para el Cuzco difiere de la de otros cronistas como Garcilaso, en el sentido de que propone que Manco Capac, primer Inca y fundador del Tawantinsuyo, fue hijo del sol y una hechicera, en vez de la luna. Mama Uaco difundió la superstición por los Andes, echando abajo la labor de San Bartolomé. Entonces la conquista se hizo necesaria para la restauración de la fe cristiana en el Perú.

La colonización, sin embargo, fue otra cosa. Los abusos y la explotación del nativo, que culminaron tras la decapitación de Tupac Amaru, el líder de la resistencia neo-incaica en 1572, ordenada por el virrey Toledo, volvieron el mundo al revés. Y es precisamente este pachakuti o terremoto cósmico lo que pretende exorcizar la carta-crónica de Guaman Poma, también documento mesiánico que anuncia el advenimiento de una nueva era ${ }^{10}$.

La segunda ilustración es parte del Buen gobierno, que examina los excesos del régimen colonial y propone una utopía política autóctona. Conserva íntegra la estructura de la primera imagen, pero transforma el mensaje. La víctima sigue siendo el indio, pero el marco temporal ha cambiado: de la era prehispánica al virreinato peruano.

El primer dibujo incluía textos verbales en función de relevo y forma de monólogo; aquí tenemos un relevo breve: "ama llapallayque llatanauaycho por amor de diosrayco"' (No me lo quites todo; te daré más) y anclaje abundante en la nominación bilingüe de los animales y los comentarios sermonarios del autor como voz " "en off' cinematográfica: presencia incorpórea que amonesta. Casi oímos el eco de las "Bienaventuranzas" en el título y el subtítulo del dibujo: "Pobre de los indios de seis animales que come que le temen los pobres de los indios en este rreyno", "estos dichos

${ }^{10}$ Sobre la intención mesiánica de la Nueva corónica véase Juan M. Ossio A., "Guaman Poma: Nueva corónica o carta al rey. Un intento de aproximación a las categorías del pensamiento del mundo andino", en Ideología mesiánica del mundo andino, ed. J.M. Ossio, Ignacio Prado Pastor, Lima, 1973, pp. 155-213. 
animales que no temen a dios desuella a los pobres de los indios en este rreyno y no ay remedio/pobre de jesucristo".

Al contrario de la primera ilustración, en este caso los animales que acosan al indio no son representaciones miméticas que deban ser entendidas literalmente. El anclaje (las etiquetas verbales que nombran a cada animal) revela la serie de equivalencias: serpiente/corregidor, león/encomendero, rata/cacique principal, tigre/español del tambo, zorra/padre de la doctrina, gato/escribano. De manera similar, el texto verbal que sigue al dibujo explicita ambos términos de cada comparación. Tenemos entonces, plenamente visibles, no sólo al plano real y el plano imaginario de cada una, sino también la palabra o frase conectiva que los vincula: son los peores que, es, son, sauen más que, es, son, son, subrayando la relación de equivalencia entre los términos. Lo que funciona como símil en el código lingüístico deviene necesariamente metáfora en el código visual. El término comparado desaparece y queda en su lugar su sustitución imaginaria. Así, en la imagen no vemos al corregidor, ni al encomendero, ni al cacique, ni al español del tambo, ni al escribano, ni al padre de la doctrina, sino a la serpiente, al león, a la rata, al tigre, al gato y a la zorra. El mensaje de denuncia gana tal fuerza que resulta avasallador. La conquista sólo ha supuesto un cambio de cárcel para el hombre andino: del régimen incaico al colonial. Pero el instrumento represivo que usaban los incas en tiempos prehispánicos para sofocar la rebeldía de los grupos étnicos asimilados al imperio, se ha convertido ahora en un sistema carcelario de vida.

Mercedes López-Baralt

Universidad de Puerto Rico, Río Piedras

\section{APÉNDICE}

/303 [305]/PRIMER CASTIGO DESTE REINO/

Castigos y preciones y cárzeles de los Yngas* para la justicia que tenían en este rreyno para el castigo de los malos:

Zancay, cárzeles de los traydores y de grandes delitos como de la ynquicición. Zancay deuajo de la tierra hecho bóbeda muy escura, dentro criado serpientes, colebras ponsoñosas, animales de leones y ticre, oso, sorra, perros, gatos de monte, buytre, águila, lichusas, sapo, lagartos.

* Las cursivas son mías. 


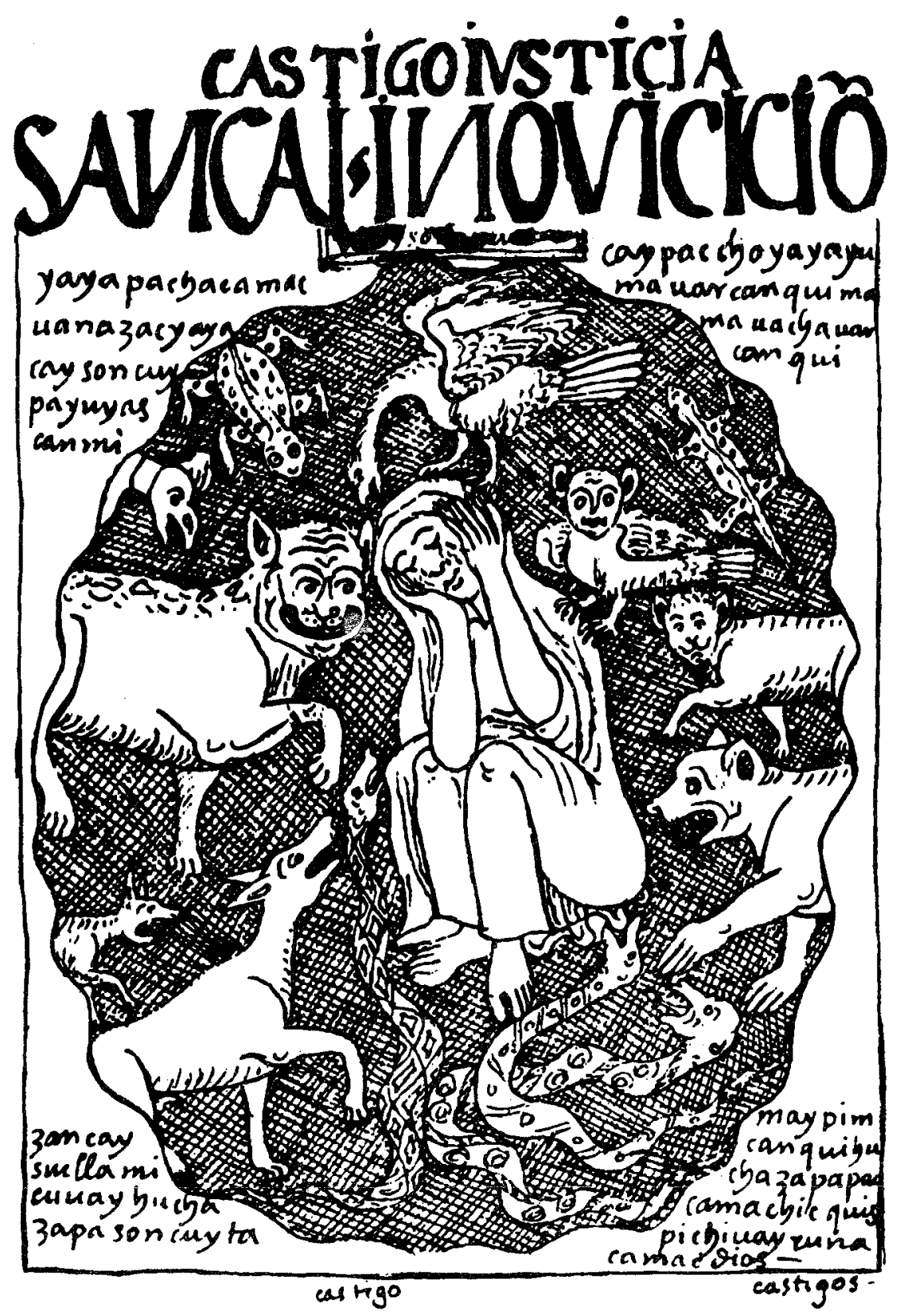

Destos animales tenía muy mucho para castigar a los uellacos y malhechores dilengüentes auca [enemigo], yscay songo [traidor], suua [ladrón], uachoc [adúltero], hanpioc [brujo], ynca cipcicac [murmuradores del Inka], apuscachac [soberbio]. A estos dichos le metían hatun huchayoc [grandes delincuentes] para que la comiesen bibo y algunos no las comía por milagro de Dios y lo tenía dos 
días enserrado. Dizen que se sustentaua con tierra y se saluaua destos animales. Luego mandaua sacar el Ynga y le daua por libre cin culpa y ací lo perdonaua y lo bolbía la honrra. Y ancí dizen quescapaua desta cárzel llamado zancay.

Estos dichos cárzeles auía en las ciudades y no podía auer en otra parte, porque no se podía sustentallo. Ni lo podía tener otros señores deste rreyno. Por lo primero, que sólo las grandes ciudades rrequería tenella y lo segundo, la magestad del Ynga era justicia mayor. Lo tersero, con este miedo no se alsaua la tierra, pues que abía señores desendientes de los rreys antigos que eran más que el Ynga. Con este miedo callauan.

\section{$/ 695[709]$ /IGLEGIA/}

Que los dichos yndios temen del corregidor porque son peores que cierpes, come gente porque le come la bida y las entrañas y le quita hazienda como brabo animal. Puede más que todos y a todos le uense y lo quita en este rreyno y no ay rremedio.

El encomendero lo temen porque es león; cogiendo, no le perdona con aquillas uñas y ser más brabo animal, no le perdona al pobre y no le agradese como feros animales en este rreyno y no ay rremedio.

Del padre de la dotrina, le temen los yndios porque son mañosos y sorras y licinciados que sauen más que la sorra de cogille y ciguille y rroballe sus haziendas y mugeres y hijas como mañoso y letrado licinciados, bachilleres. Por eso se llaman letrados; el buen sorra es dotor y letrado. Y ancí destrúe en este rreyno a los pobres de los yndios y no ay rremedio.

Del escriuano le temen los yndios porque es gato cazador, azecha y trauaja y lo coge y no le haze mene[a]r hasta cogello; en cogiendo, no le haze menear y da priesa de cogérsela y no ay rremedio del pobre de los yndios.

De los españoles del tanbo [mesón], pasageros que no temen a Dios ni a la justicia, lo temen los yndios porque son tigre, brabo animal. En llegando al tanbo, taca mitaya, toma mitayo, taca rrecaudo y serbicios y le toma ualor de dies pesos y se lo gasta y no le paga y no mira ci es alcalde o cacique prencipal o pobre yndio. Le da de muchos palos y le quita quanto tiene y se los lleua, acimismo en los pueblos y en las estancias y es peor que los demás animales y no ay rremedio de los pobres yndios.

De los caciques prencipales que se hazen de yndio bajo, cacique y mandoncillos de dies yndios los cinco se hazen curaca, prencipal. Déstos temen los yndios pobres porque son rratones. Lo hurtan de día y de noche sus haziendas; cin que nadie lo cienta hurta y lo rroba. Pide demás de la taza y ricachicos, ysangas [cestillo], fruta, plata y otras comidas y le gasta de las comunidades y de sapci quanto puede, que cinifica mayor que todos los animales porque de día y de noche nunca para y no ay rremedio de los pobres yndios deste rreyno.

Y ancí de la cierpe, león, ticgre, sorra, gato, rratón, destos seys animales que le come al pobre del yndio, no le dexa menearse y le desuella en el medio y no ay menear. Y entre estos ladrones unos y otros entre ellos se ayudan y se faboresen. Y ci le defiende a este pobre yndio el cacique prencipal, le comen todos ellos y le mata. Y ací el cacique prencipal no le conosca de causas ciuiles, criminales porque son enemigos mortales en este rreyno. 


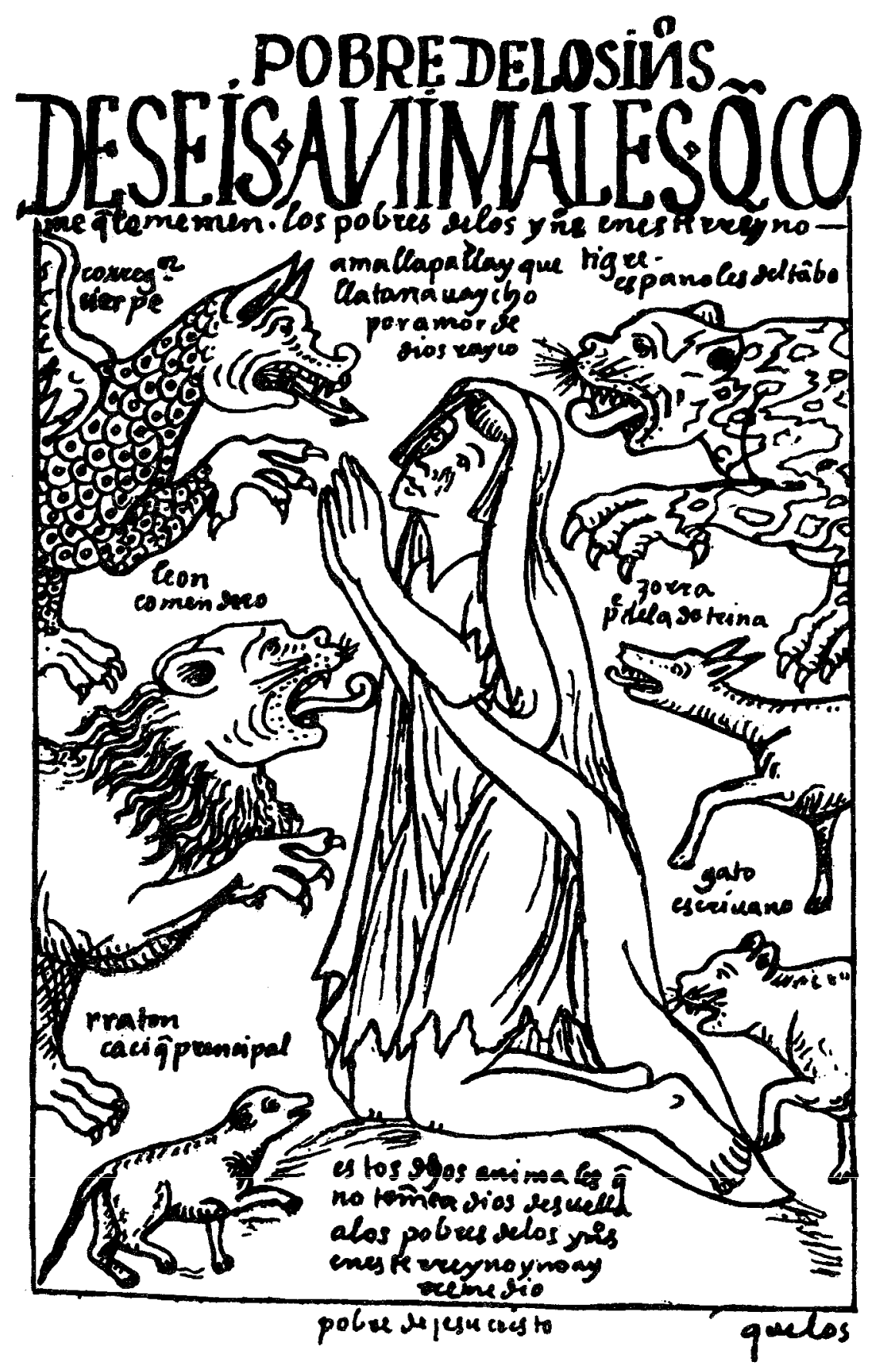

